\title{
Political Knowledge and Media Use in the Netherlands
}

\author{
P. G. J. Hendriks Vettehen, C. P. M. Hagemann \\ and L. B. van Snippenburg
}

Data from a nationwide survey of the year 2000 were used to investigate the level and distribution of political knowledge among the Dutch population. The influences of four demographic and socio-economic characteristics on political knowledge were estimated as well as the associations of the latter with the use of various media contents. In order to measure political knowledge adequately, a so-called Mokken scale was constructed contending five cumulative items. The empirical results indicated that political knowledge is not equally distributed among the Dutch population by a long way. A large part of that population, about 40 per cent, is hardly or not aware of simple political facts. Education, and to a lesser extent sex, age, and income appeared to be substantial determinants of political knowledge. The results also showed that citizens, independently of their level of education, age, sex, and income do use specifically politically oriented media-contents more frequently to the extent that they have more political knowledge.

\section{Introduction}

Two opposite views on democracy can be discerned in political theory. One view considers 'participatory democracy', the other 'elite pluralism' as the optimal model for western societies. A main characteristic of the model of participatory democracy is the direct and active participation of all citizens in politics. However, according to the model of elite pluralism, citizens should only be involved in politics from a distance, they should leave the actual practice of it to elected representatives (Dahl, 1989; Davis, 1990; Joslyn, 1990).

The two views on democracy include different assumptions concerning the needed level and distribution of political knowledge among citizens. Proponents of participatory democracy take as a starting point that large portions of the population can acquire adequate knowledge of politics in order to be able to participate in it on a daily basis. In contrast, proponents of the 'elite pluralism' model assume that large groups of the population are insufficiently aware of the political process anyway, amongst other reasons because policy making and connected procedures are enacted on abstract levels and differ too much from decision making in everyday life. For this reason, citizens should leave the practice of actual politics to elected political professionals. In this view, appropriate election procedures have to secure proper representation of the various societal groups and their interests in politics. However, also in this view it is considered necessary that citizens have at least basic political knowledge. They should have enough knowledge of political institutions and actors in it to be able to watch the elected 'elites', and to assess whether or not they act in an accountable way according to the democratic expectations (Dahl, 1989; Edelman, 1988; Davis, 1990; Joslyn, 1990).

Although both distinguished views on democratic politics bear on presumptions about the level and distribution 
of political knowledge among citizens in today's democracies, knowledge on this issue is limited. In the USA, political knowledge has been shown to be generally low and unevenly distributed among the population (Delli Carpini and Keeter, 1996). Less is known about the situation in most western European countries. Therefore, empirical research is needed.

Preceding research on political knowledge has led to a variety of measures of political knowledge. Occasionally debates have risen on the content and format of these measures (e.g. Delli Carpini and Keeter, 1993, 1996; Vis, 1995; Mondak, 2001). However, most measures are comparable as to their focus on rather similar knowledge of basic and discrete political facts, figures and events. Political knowledge may thus be distinguished from more composite concepts, notably from 'political sophistication'. Although this latter concept is not undisputed (cf. Guo and Moy, 1998), it may be regarded as encompassing not only the number and diversity of political cognitions, but also their organization into 'political schemata' (Luskin, 1987).

Summarizing, irrespective of their view on democracy, political theorists agree that citizens should at least know some basic facts about the core institutions of democracy and about the actors actually engaged in politics. Without such knowledge, citizens would not be able to survey the political course of things slightly or to participate in a marginal sense in the democratic process. Therefore, empirical research on the level and the distribution of such knowledge among the population is important. In the present study we refer to this basic knowledge whenever we use the words political knowledge.

\section{Research Questions}

The present study focuses on the political knowledge among the population of a western democracy, i.e. the Netherlands. Based on data of successive nationwide election questionnaires between 1977 and 1989, Wittebrood (1990) showed that large categories of the Dutch population had hardly any knowledge of political matters.

As a follow-up, the first question to be answered in the present study concerns the average level and distribution of political knowledge among the Dutch population in the year 2000. ${ }^{1}$ Next, the relations of political knowledge with four core socio-structural determinants are assessed, notably sex, age, level of education, and income. Finally, the focus of the analysis shifts to the complicated relations between the political knowledge of citizens and their daily media use. These relations are especially worth studying since the mass media, particularly the news media, are by far the most important sources of political information in contemporary western societies (Miller and Asp, 1985; Delli Carpini and Keeter, 1996).

\section{Hypotheses}

From preceding studies on political knowledge, we have identified four demographic and structural variables that theoretically may predict levels and distributions of political knowledge, and that may apply to the Dutch case: $^{2}$ sex, age, educational level, and income.

Delli Carpini and Keeter $(1993,1996)$ as well as Verba and colleagues (1997) found that women in the USA have, on average, a lower level of political knowledge than men. Wittebrood (1992) reached a similar result in her research in the Netherlands. According to Verba et al. (1997), this difference in knowledge between the sexes could possibly be a result of the cultural norm that politics is especially a man's business, which is still dominant in western countries. Although during the past decades somewhat more women have made their entrance into politics, most boys as well as girls have been brought up in a political cultural climate that is dominated by men. Added to this is the situation that women, once they have reached adulthood and participate in the labour market, often occupy less managerial positions than men, and are more often employed in care and direct service functions than men. Such 'womanly' occupations include more involvement in concrete daily-life matters than in global and distant political matters (cf. Delli Carpini and Keeter, 1996; Hermans and Van Snippenburg, 1996). Therefore, women are supposed to be less inclined than men to identify themselves with, and be interested in, politics. The result is a lower level of political knowledge on average among women than among men.

A clear relation between age and political knowledge may seem difficult to predict, because age may represent both life-cycle effects and generational effects (cf. Delli Carpini and Keeter, 1996). Life-cycle effects are based on the idea that the older citizens are, the more they have had the opportunity to acquire knowledge on politics. Explained more in detail, it can be assumed that political knowledge accumulates as life goes on. A start in the acquisition of political knowledge is made during primary and especially secondary education. Having reached adulthood, people consume political information from the news and other programs on radio and 
television, from newspapers, etc. Most citizens talk at least sometimes, some of them even daily, about politics with family, friends, colleagues and neighbours. Such media usage and small conversations in daily life continue through the life span. It seems therefore reasonable to expect some accumulation of political knowledge with increasing age as a consequence of this more or less steady flow of political information that reaches people by way of the media and informal talks.

Generational effects are more difficult to predict. Delli Carpini and Keeter (1996) noted that the older cohorts in the USA have had less opportunity to receive a higher education than the younger cohorts. This may be considered as a disadvantage in chances to learn about politics. However, the younger cohorts in the USA appeared to display a disinterest in politics, which may result in a more negative attitude towards learning about politics. Both observations may also apply to the Netherlands, which makes it difficult to formulate straightforward predictions about a generational effect.

Findings from previous studies range from the absence of a significant relation between age and political knowledge (Wittebrood, 1992), to a moderately positive relation (Delli Carpini and Keeter, 1996) and even a strong positive relation (Guo and Moy, 1998). For the present research, we hypothesize that the overall effect of age on political knowledge is positive.

In 1986, Neuman concluded that education is an important predictor of political knowledge. He reasoned that the higher educated citizens are generally better equipped to grasp abstract matters than the lower educated ones, since their thinking can reach higher levels of so-called 'cognitive complexity'. Therefore, the higher educated elaborate political information less superficially, which will increase their political knowledge. Other reasons for expecting education to be the most important predictor of political knowledge are the transmission of knowledge and the socializing of students in politics, both taking place at school (Delli Carpini and Keeter, 1996). Research in the USA (cf. Delli Carpini and Keeter, 1996; Guo and Moy, 1998; Price, 1999) and the Netherlands (Wittebrood, 1992) actually showed the positive relation between education and political knowledge that is to be expected on the basis of such reasoning.

The study by Delli Carpini and Keeter (1996) points to the socio-economic variable 'income' as a final predictor of political knowledge. Their main explanation for this finding is that a high income facilitates access to relatively expensive media as sources of political knowledge, notably newspapers, political journals, and the internet. As an additional explanation, one may argue that a high income facilitates access to the political process itself, ${ }^{3}$ which also provides opportunities to learn about politics.

On the basis of theoretical considerations and empirical findings so far discussed we formulate the following four-fold hypothesis as a summary:

H1: The level of political knowledge is higher to the extent that one (i) belongs to the male sex, (ii) is older, (iii) has a higher level of education, and (iv) has a higher income.

Besides this four-fold hypothesis concerning the effects of background variables on the level of political knowledge, we will formulate a second hypothesis concerning the relations between peoples' media consumption and their level of political knowledge. In this hypothesis, a third variable will play a part: the degree to which the media content that people consume elaborates on politics.

In order to arrive at such a hypothesis, we start with the common sense notion that people gain at least some knowledge from consumption of political media content. From this we may expect a positive relation between the amount of peoples' consumption of political media content and their level of political knowledge.

However, starting from information processing theory, we may also expect that the relation between such media consumption and political knowledge depends on a third variable: the degree to which the media content elaborates on politics. Information processing theory stresses the importance of cognitive schemata to the processing of information. The more existing schemata are activated by incoming information, the more deeply the information will be processed and the better it will be stored subsequently. Mass media are able to anticipate upon this process by presenting information in a context that is familiar to the audience, that will activate existing schemata and thus will improve the processing of the information (cf. Woodall et al., 1983). Applying this notion to the relation between the level of political knowledge and the consumption of various media contents, we predict that the more media content elaborates on politics, the more people will learn about politics while consuming such media content, i.e. the more positive the relation between media consumption of such content and political knowledge will be.

So far, we have developed a provisional three variable hypothesis with 'political knowledge' as the dependent variable and 'media consumption' and 'degree to which the media content elaborates on politics' as the independent variables. However, taking another viewpoint, we may 
reverse the causal direct in this interactive model. In this model, we posit 'media consumption' as the dependent variable and 'political knowledge' and 'degree to which the media content elaborates on politics' as the independent variables. The argument draws heavily on van Snippenburg (1992), who developed it to explain his findings concerning the consumption of political information in newspapers and on television. It proceeds as follows.

Much mass media content hardly touches upon political issues or only treats them superficially. People hardly need any knowledge of politics in order to comprehend such content. Therefore, for mass media content that does not elaborate on politics, we predict that political knowledge does not influence peoples' amount of consumption. In contrast, the more deeply a media content goes into politics, the more knowledge of politics people need to comprehend and enjoy that content. For this reason, for mass media content that does elaborate on politics, we predict that political knowledge does influence peoples' amount of consumption. In all, we may also predict provisionally that the level of political knowledge hardly influences the consumption of media content that does not elaborate on politics, whereas the level of political knowledge positively influences the consumption of media content that does elaborate on politics.

Combining the two provisional hypotheses we developed, we anticipate a reciprocal process. On the one hand, people consuming media acquire more political knowledge as the media content elaborates more on politics. On the other hand, as people have more political knowledge, they consume more media content that elaborates more intensely on politics, in addition to media content that less or hardly elaborate on politics and that are used by all sections of the population, i.e. including those with low levels of political knowledge.

The data in the present study are cross-sectional and consequently do not allow for testing the reciprocity of the relation between media consumption and political knowledge. However, they do allow for testing both the expected overall positive relation between media consumption and political knowledge and the expected moderating effect of the variable media content. These expectations are expressed in the following three-variable hypothesis.

$\mathrm{H} 2$ : The relationship between political knowledge and media consumption is more positive to the extent that the media content elaborates more on politics.

When testing this hypothesis, we have to account for disturbing effects of the variable 'medium type' (especially television versus radio versus print) on the process of knowledge acquisition by means of media consumption. The scientific discussion concerning the effectiveness of various media types in learning processes is not yet resolved (cf. Guo and Moy, 1998). For instance, learning experiments on students point to print media as the most effective medium, whereas experiments on children point to television as the most effective medium (cf. Walma van der Molen, 1998). As far as consuming information through one medium leads to more knowledge acquisition than consuming the same information through another medium, the testing of the second hypothesis will be disturbed. For this reason we will test this hypothesis separately for television, radio and print.

\section{Method}

\section{Data}

Data for the present analyses were taken from a nationwide Dutch survey ('Media Use in the Netherlands') conducted by the Department of Communication Science of the University of Nijmegen between January and March, 2000. The survey used a two-stage random sample of people between 18 and 81 years old. In the first stage, a number of municipalities were selected in such a way that the distribution of regions (North, East, South and West) and the degree of urbanization (ranging from small villages to big cities) would be represented proportionately to the national distribution. In the second stage, people aged from 18 up to 81 were randomly selected from the registers of selected municipalities and interviewed by means of a standardized questionnaire (mostly closed and some open questions). The number of respondents was 825 . The response rate was 43.2 per cent. The sample turned out to be representative of the Dutch population with respect to sex, age and marital status as well as to combinations of these characteristics. ${ }^{4}$

\section{Measurement}

In the introductory section, we defined political knowledge as basic knowledge about the core institutions of democracy and the actors actually engaged in politics. In order to measure this concept in a one-dimensional way, five (presumed) cumulative questions about politics were included in the survey. Two of the questions addressed knowledge of the Dutch political structure, the other three addressed knowledge of current political affairs. The wording of the questions (translated into 
English) are represented in Appendix 1. A so-called Mokken scale analysis (Mokken, 1971) was applied to the respondents' answers in order to construct a scale of political knowledge and to test the one-dimensional character and the reliability of it. The constructed scale came up to the usual requirements: the coefficient for one-dimensionality reached 0.44 (Loevinger's $\mathrm{H}$ ) and the one for reliability reached 0.69 (Rho). With this Mokken scale the respondents could be classified into six levels of political knowledge.

The obtained result of a one-dimensional and reliable five-item scale is in accordance with results from an earlier methodical study of Delli Carpini and Keeter (1993) in the USA. These authors evaluated the validity and reliability of both a five-item and a twenty-item scale. On the basis of the findings and their ideas about the applicability of such scales composed out of questionnaire data, the authors concluded: 'While we recommend this five-item index, the more general point from this analysis is that very short scales composed of carefully chosen items can measure political knowledge with an acceptable level of reliability and validity' (Delli Carpini and Keeter, 1993: 1202).

In addition to the questions on political knowledge, the survey contained questions on demographic and socio-economic characteristics of respondents, notably sex, age, level of education, and income, as well as questions on media usage. The questions on media usage are in large part similar to those regularly used in surveys on media usage (cf. Arts et al., 1989; Hendriks Vettehen et al., 1995) and in other nationwide surveys, such as election studies (Aarts et al., 1999). In order to construct a variable 'extent to which the media content used elaborates on politics', we categorized the media use variables under the following headings: (i) 'general media use', (ii) 'specific media use', and (iii) 'specific political media use'. The category 'general media use' included the variables 'time watching television', 'time listening radio', and 'time reading newspapers', each measured by openended questions as the average consumption in minutes per day. The variable 'reading newspaper' turned out to be skewed, which was caused by the overrepresentation of respondents who spend a lot of time with newspaper reading. In order to correct for this, a transformation to $\mathrm{z}$-scores was carried out to reach a normal distribution. The category 'specific media use' included 'watching television news' and 'listening to radio news'. The category 'specific political media use' included 'watching political programs on television', 'listening to political programs on the radio' and 'reading political articles in the newspaper'. The variables in the categories 'specific media use' and 'specific political media use' were all measured by closed questions with five answering categories, ranging from 'never' to '(almost) always'.

\section{Results}

\section{Mean Level and Distribution of Political Knowledge}

In order to answer the research question concerning the level of political knowledge in the Netherlands in the year 2000, i.e. its mean and its distribution, some statistical characteristics as measured by the used scale of political knowledge are presented below. Table 1 shows the frequencies of the scores on the scale.

The level of political knowledge among the respondents ranges from 0 to 5 ; the mean is 2.12 and the standard deviation is 1.70 . As can be seen from the frequencies in Table 1 , as well as from the relation between the range and the standard deviation, the distribution is somewhat flat. In that sense we can state that political knowledge is not equally divided (divided by chance, which should have resulted in a normal distribution) among the Dutch population in the year 2000 .

Because of the divergence of this distribution from normality we had to be cautious with the results of the subsequent multiple regression and partial correlation analyses. Therefore we performed these analyses twice, once using the original variable 'political knowledge' and once using a normalized variable. The results of both series of analyses did not differ substantially. In the following tables we report only the results with the original variable.

\section{Level of Age, Sex, Education, and Income as Determinants of Political Knowledge}

Preceding the test of the hypotheses, we ascertained that the correlations between the variables in our analyses

Table 1 Frequencies of scores on the political knowledge scale

\begin{tabular}{lrr} 
& $\mathbf{n}$ & \% \\
\hline Scale value 0 & 198 & 24.0 \\
Scale value 1 & 141 & 17.1 \\
Scale value 2 & 157 & 19.0 \\
Scale value 3 & 130 & 15.8 \\
Scale value 4 & 92 & 11.2 \\
Scale value 5 & 107 & 13.0 \\
Total & 825 & 100.0 \\
\hline
\end{tabular}


did not deviate from linearity. Next, we computed the zero-order correlations of political knowledge with level of sex, age, education, and income. ${ }^{5}$ Expressed in Pearson's coefficients, these correlations were $0.23,0.09$, 0.36 , and 0.19 , respectively (all significant, $P<0.01$, one-sided). To assess the independent influences of level of sex, age, education, and income on political knowledge, a multiple regression analysis was performed with political knowledge as the dependent, and the four background characteristics as the independent variables.

From Table 2 we can read that level of sex, age, education, and income contribute to the explanation of political knowledge $(P<0.01$, one-sided) independently of each other. The relative contribution of level of education is considerable ( $\beta$ is 0.35 ), whereas those of sex $(0.18)$, age $(0.18)$, and income $(0.13)$ are moderate. The proportion explained variance $\left(\mathrm{R}_{\text {adj }}^{2}\right)$ is 0.21 . These results support our first four-fold hypothesis.

Additionally, we may observe that the effect of sex is only slightly affected by controlling for age, education, and income ( 0.23 zero-order; 0.18 multivariate). This may be seen as surprising since the generally found positive connection of sex with political knowledge is sometimes explained with reference to the generally higher educational level of men (cf. Peeters and Heuvelman, 1996). The present analysis hardly confirms the role of educational level as a mediating variable.

Finally, we may note another striking finding: the effect of age on political knowledge, controlled for level of sex, education, and income is 0.18 , while the zeroorder correlation is only 0.09. A suppression effect might explain this: at the level of zero-order correlations, we hypothesized that an indirect negative influence of age on political knowledge via the lower level of education that elderly people, on average, have, could have suppressed the direct positive influence of age on political knowledge.

Table 2 Regression of sex, age, education, and income on political knowledge

\begin{tabular}{lrccc} 
Variable & b & S.E. b & Beta & $\begin{array}{c}\text { Sig } \\
\text { (one-sided) }\end{array}$ \\
\hline Intercept & -2.44 & 0.38 & & 0.00 \\
Sex & 0.62 & 0.11 & 0.18 & 0.00 \\
Age & 0.02 & 0.00 & 0.18 & 0.00 \\
Education & 0.63 & 0.07 & 0.35 & 0.00 \\
Income & 0.09 & 0.02 & 0.13 & 0.00 \\
\hline
\end{tabular}

$R^{2}$ adj. $=0.21$.

\section{Media Use and Political Knowledge}

The second hypothesis predicts that the correlation between political knowledge and media consumption will be more positive to the extent that concerning media content elaborates more on politics. This hypothesis has been tested by correlating political knowledge with consumption of the three distinguished categories of media content (see Method section) for distinct types of media (television, radio and newspapers respectively).

From Table 3 we can read that the zero-order correlation between political knowledge and watching specific political television programs on television is higher than the correlation between political knowledge and watching television newscasts $(0.30$ versus 0.03$)$. This difference is statistically significantly, as the different subscripts of the coefficients in Table 3 indicate. Moreover, this latter correlation is higher than the one between political knowledge and watching television in general $(0.03$ versus -0.19$)$. A similar pattern is apparent for listening to the radio. The correlation between political knowledge and listening to political radio programs is 0.26 , whereas the correlation with listening to radio news is 0.03 , and the correlation with listening to the radio in general is -0.10 . The correlation between political knowledge and reading articles on politics in newspaper is 0.43 , whereas the correlation with reading newspaper in general is 0.25 . The comparison of the correlations shows that for each type of medium separately the correlation of political knowledge with media

Table 3 Zero-order correlations and partial ${ }^{a}$ correlations of political knowledge with media use variables

$\begin{array}{cc}\begin{array}{c}\text { Zero-order } \\ \text { correlations }^{b}\end{array} & \begin{array}{c}\text { Partial } \\ \text { correlations }^{b}\end{array}\end{array}$

\begin{tabular}{lrr}
\hline Watching television & & \\
General & $-0.19_{\mathrm{a}}$ & $-0.06_{\mathrm{x}}$ \\
News & $0.03_{\mathrm{b}}$ & $0.05_{\mathrm{y}}$ \\
Politics & $0.30_{\mathrm{c}}$ & $0.24_{\mathrm{z}}$ \\
Listing to radio & \\
General & $-0.10_{\mathrm{a}}$ & $-0.05_{\mathrm{x}}$ \\
News & $0.03_{\mathrm{b}}$ & $0.00_{\mathrm{x}}$ \\
Politics & $0.26_{\mathrm{c}}$ & $0.17_{\mathrm{y}}$ \\
Reading newspaper & & \\
General & $0.25_{\mathrm{a}}$ & $0.15_{\mathrm{x}}$ \\
Politics & $0.43_{\mathrm{b}}$ & $0.31_{\mathrm{y}}$ \\
\hline aControlled for sex, age, education, and income. & \\
${ }^{b}$ Per column and per type of medium, coefficients with different subscripts differ \\
significantly from each other $(P<0.01$, one sided; see Blalock, 1979: 425$)$.
\end{tabular}


consumption increases to the extent that the media content elaborates more on politics.

In order to control these results for spurious relationships, partial correlations between political knowledge and the media consumption variables have been calculated controlling for level of sex, age, education, and income. As can be read from Table 3, the differences between the partial coefficients display a pattern that is, by and large, analogous to the pattern of the zero-order correlations. From this we conclude that the second hypothesis is corroborated.

\section{Discussion}

In the introduction we stated that whatever view on democracy is adopted, a certain level of basic political knowledge among all citizens is generally considered important for the democratic process to run well. The results at hand indicate that political knowledge is quite unequally distributed in the Netherlands. Moreover, and in line with our first hypothesis, educational level and to a somewhat lesser extent, sex, age, and income appear to be substantial determinants of political knowledge. These results point to differences in political knowledge between citizens who are relatively well informed about politics (especially the higher educated, the rich, the elderly, and men) and those who are badly informed about politics (the less educated, poor, the young, and women). These findings are quite similar to those reported for the USA by Delli Carpini and Keeter (1996).

The differences in political knowledge between citizens may be evaluated from at least two points of view. Adopting the perspective of many politicians, the results seem to support their concern that large parts of the citizenry just don't care about politics. For instance, the lower level of political knowledge among women could reflect a lack of interest in the political process. However, adopting the perspective of many women, the results seem to support their complaints that political debates in parliament and other institutions hardly reflect their concrete concerns. In line with this latter view, the relatively small degree of political knowledge among women could be at least partially explained by the complaints of women that the actual political processes and the ways they are presented in the mass media, have no relation whatsoever to women's affairs in everyday live (cf. Hendriks Vettehen et al., 2004).

Another finding from our study is that the relationship between political knowledge and most types of media consumption appears to be positive, which is in line with the generally perceived importance of mass media as the citizen's main source of political knowledge. However, and in line with our second hypothesis, the relationship between political knowledge and media consumption appears to be more positive as the media content elaborates more on politics. We might evaluate this result from the same two points of view. In the eyes of the worried politicians, the results could at worst indicate a vicious circle: people with little political knowledge mainly consume that media content that does not teach them a great deal about politics, while people with much political knowledge choose media content that contributes to more general and even more sophisticated knowledge. Delli Carpini and Keeter (1996: 287) referred to this circle with the phrase 'knowledge begets knowledge', the phenomenon that improvements of the information environment primarily serve those who are already well informed. Studies being based on such a perspective try to establish to what extent such 'knowledge gaps' do exist and whether causal mechanisms such as these are actually underlying it (Viswanath and Finnegan, 1996).

In the eyes of the complaining citizens, the results on our second hypothesis might support their view that the complicated political spectacle, which reaches them through the media, is exclusively interesting and informative to highly educated and well-earning, middleaged men: the part of the population that is also most prominent in this spectacle (cf. Gallagher et al., 2000). Studies that are based on such a perspective point to another causal mechanism underlying 'knowledge gaps': the extent to, and the ways in which especially the less educated, the young, women, and the poor are present in political media coverage could decrease the attractiveness and relevance of political news to these categories of the population, thus enhancing the 'political knowledge' gaps (cf. Carter et al., 1998).

Two remarks concern the limitations of the present study. First, the present data only allowed for the testing of a positive relation between types of media consumption and political knowledge. The reciprocity of the relationship could not be studied. As a consequence, the discussion above concerning the causal mechanisms underlying knowledge gaps has an interpretative character. Future studies may aim at disentangling the causal processes underlying the positive relation, notably by using a panel design. Second, as the present state of theory did not allow us to formulate a hypothesis concerning the relative strength of the relations between political knowledge and the three media types (television, radio, and newspaper), we could only control for the variable media type instead of incorporating it into our model. 
A quick glance at Table 3 reveals that the correlations of political knowledge with newspaper usage are generally stronger than those with television and radio usage. However, without additional research into the underlying mechanisms these differences are hard to explain properly.

A final remark concerns the measurement of political knowledge in our research. In line with findings by Delli Carpini and Keeter (1993), just five questions appeared to be sufficient to construct a cumulative scale meeting the requirements of one-dimensionality and reliability. Moreover, the fact that we did not have to reject our hypotheses concerning the relations between political knowledge and other concepts gives some credence to the construct validity of the scale. For this reason, we consider it a simple device for further research on political knowledge in western democracies. With some adjustments, it might even become a useful device for monitoring trends in the distribution of political knowledge. The studies on the causal mechanisms possibly underlying knowledge gaps might provide us with strategies for bridging the gaps between categories of citizens, as well as bridging the gaps between citizens and politics. Continuous research on the distribution of political knowledge might help to evaluate the success of these strategies.

\section{Notes}

1. All analyses are restricted to knowledge of national politics since our considerations on democratic models so far mainly concern politics at the national level.

2. For instance, in the Delli Carpini and Keeter (1996) study, the variables of region and race are significant predictors of political knowledge. In a small country like the Netherlands, a distinction in regions theoretically hardly makes sense in studying political knowledge. With respect to race, the sample at hand contained data on only $n=51$ persons born in foreign countries. This group was far too heterogeneous to justify general conclusions. However, to control for ethnicity, we repeated all analyses, excluding these $n=51$. The results differed only marginally.

3. The sometimes expensive memberships of political parties, trade unions, or pressure groups may provide an explanation for Delli Carpini and Keeter's observation that political organizations are ineffective in mobilizing the economically disadvantaged (1996: 213-217).

4. For further information on the design of the survey, sample and data, contact the authors.
5. The simple distributions (means and variances) of political knowledge on each of the demographic and socio-structural variables are presented (see Appendix 2). In the table, the variables of age, education, and income were categorized.

\section{References}

Aarts, K., van der Kolk, H. and Kamp, M. (1999). Dutch parliamentary election study 1998. Documentation. Enschede: NIWI/Steinmetz Archive/Dutch Electoral Research Foundation (SKON).

Arts, K., Hollander, E., Renckstorf, K. and Verschuren, P. (1989). Grootschalig veldonderzoek naar mediauitrusting, media-exposure en mediagebruik in Nederland 1989 Verantwoording en beschrijving van de data. [Large-scale field research on media equipment, media exposure and media use in the Netherlands 1989]. Nijmegen, the Netherlands: Katholieke Universiteit Nijmegen, Instituut voor Toegepaste Sociale Wetenschappen.

Blalock, H. M. Jr (1979). Social statistics. Tokyo, Japan: McGraw-Hill Kogakusha, Ltd.

Carter, C., Branston, G. and Allen, S. (1998). News, gender and power. London, UK: Routledge.

Dahl, R. A. (1989). Democracy and its critics. New Haven, CT: Yale University Press.

Davis, D. (1990). News and politics. In Swanson, D. and Nimmo, D. (Eds), New directions in political communications: a resource book. London, UK: Sage Publications, pp. 147-184.

Delli Carpini, M. X. and Keeter, S. (1993). Measuring political knowledge: putting first things first. American Journal of Political Science, 37, 1179-1206.

Delli Carpini, M. X. and Keeter, S. (1996). What Americans know about politics and why it matters. New Haven/ New York: Yale University Press.

Edelman, M. (1988). Constructing the political spectacle. Chicago, IL: The University of Chicago Press.

Gallagher, M., Spears, G. and Seydegart, K. (2000). Who makes the news. The Global Media Monitoring Project 2000. London, UK: The World Association for Christian Communication.

Guo, Z. and Moy, P. (1998). Medium or message? Predicting dimensions of political sophistication. International Journal of Public Opinion Research, 10, 25-50.

Hendriks Vettehen, P. G. J., Need, Y., Renckstorf, K., van Snippenburg, L. B. and de Vos, B. (1995). Media use in the Netherlands, 1994. Documentation of a national survey. Nijmegen, the Netherlands: Katholieke Universiteit Nijmegen, Instituut voor Toegepaste Sociale Wetenschappen.

Hendriks Vettehen, P. G. J., Schaap, G. J. and Schlösser, S. (2004). What men and women think while watching 
the news: an exploration. Communications, 29, 235-251.

Hermans, E. and van Snippenburg, L. B. (1996). Women's use of TV news. In Renckstorf, K., McQuail, D. and Jankowski N. (Eds), Media use as social action. London, UK: John Libbey, pp. 139-150.

Joslyn, R. (1990). Election campaigns as occasions for civic education. In Swanson, D. and Nimmo, D. (Eds), New directions in political communications: a resource book. London, UK: Sage Publications, pp. 86-119.

Luskin, R. C. (1987). Measuring political sophistication. American Journal of Political Science, 31, 856-899.

Miller, A. H. and Asp, K. (1985). Learning about politics from the media: a comparative study of Sweden and the United States. In Kraus, S. and Perloff, R. M. (Eds), Mass media and political thought: an information-processing approach. Beverly Hills, CA: Sage.

Mokken, R. J. (1971). A theory and procedure of scale analysis. With applications in political research. Den Haag, the Netherlands: Mouton.

Mondak, J. J. (2001). Developing valid knowledge scales. American Journal of Political Science, 45, 224-238.

Neuman, W. R. (1986), The paradox of mass politics: knowledge and opinion in the American electorate. Cambridge, MA: Harvard University Press.

Peeters, A. and Heuvelman, A. (1996). Is er werkelijk een zwakker geslacht als het om televisienieuws gaat? [Is there really a weaker sex in recalling television news?] Tijdschrift voor communicatiewetenschap, 24, 75-85.

Price, V. (1999). Political information. In Robinson, J. P., Shaver, P. R. and Wrightsman, L. S. (Eds), Measures of political attitudes. San Diego, CA: Academic Press, pp. 591-639.

van Snippenburg, L.B. (1992). Politiek op televisie en in de krant: sociale kenmerken en informatie-interesse van kijkers en lezers [Politics on television and in the newspaper: social characteristics and viewer's and reader's information interest]. Sociologische Gids, 29, 82-94.

Verba, S., Burns, N. and Schlozman, K.-L. (1997). Knowing and caring about politics: gender and political engagement. The Journal of Politics, 59, 1051-1072.

Vis, C. P. M. (1995). Politieke kennis en politieke vorming. [Political knowledge and political education]. Groningen, the Netherlands: Wolters-Noordhoff.

Viswanath, K. and Finnegan, J. R. (1996). The knowledge gap hypothesis: twenty-five years later. In Burleson, B. R. (Ed.). Communication Yearbook 19. Newbury Park: Sage, pp. 187-227.

Walma van der Molen, J. H. (1998). Children's and adults'recall of television versus print news: is print really better? Communications, 23, 475-490.

Wittebrood, K. (1990). De onwetende burger? Politieke kennis van de Nederlandse burger [The ignorant citizen? The Dutch citizen's political knowledge]. Namens, 5, 18-24.

Wittebrood, K. (1992). Het politieke kennisniveau van de Nederlandse burger [The Dutch citizen's level of political knowledge]. Acta Politica, 27, 135-159.

Woodall, W. G., Davis, D. K. and Sahin, H. (1983). From the boob tube to the black box: television news comprehension from an information processing perspective. Journal of Broadcasting, 27, 1-23.

\section{Authors' Addresses}

Paul G. Hendriks Vettehen, NICoR - Nijmegen Institute for Communication Research, PO Box 9104, $6500 \mathrm{HE}$ Nijmegen, the Netherlands. Tel.: +31 24 6313094; Fax: +31 24 6313073; Email: p.hendriksvettehen@ maw.ru.nl

C. P. M. Hagemann, Nijmegen Institute for Communication Research, Radboud University Nijmegen, the Netherlands.

L. B. van Snippenburg, Nijmegen Institute for Communication Research, Radboud University Nijmegen, the Netherlands.

Manuscript received: November 2003. 


\section{Appendix 1}

Questions on political knowledge (translated from the Dutch language) in the national survey 'Media Use in the Netherlands' in the year 2000. The percentage of correct answers is represented below each question.

- Can you tell me which political parties participate in the current governmental coalition?

$63.2 \%$ correct answers

- Can you tell me to what political party Mr. Zalm, the current Minister of Finance, belongs?

$60.0 \%$ correct answers

- Can you tell me the number of chairs in the Lower Chamber of Parliament?

$40.3 \%$ correct answers

- Can you tell me which political institution (or institutions) in our country has (have) lawmaking power?

$40.4 \%$ correct answers

- Can you tell me who the name of the current chairman of the Lower Chamber of Parliament?

$37.1 \%$ correct answers

\section{Appendix 2}

Table A1 Political knowledge by sex, age, education, and income

\begin{tabular}{lccc} 
Variable & Mean & S.D. & n \\
\hline Sex & & & \\
Female & 2.71 & 1.66 & 427 \\
Male & 3.56 & 1.64 & 398 \\
Age & & & \\
$18-34$ & 2.94 & 1.66 & 260 \\
$35-54$ & 3.15 & 1.67 & 384 \\
$55+$ & 3.33 & 1.80 & 179 \\
Education & & & \\
Primary school & 1.92 & 1.26 & 51 \\
Low educational level & 2.70 & 1.65 & 227 \\
Middle educational level & 2.91 & 1.58 & 232 \\
High educational level & 4.00 & 1.58 & 248 \\
Income in Euros & & & \\
Less than 1361 & & & \\
1362-1815 & 1.80 & 1.65 & 233 \\
1816-2269 & 1.90 & 1.63 & 200 \\
More than 2269 & 2.45 & 1.71 & 181 \\
& 2.75 & 1.64 & 157 \\
\end{tabular}

${ }^{a}$ In the original question the income was asked in the former Dutch currency 'Guilders'; for the classification in this table, we made a conversion into Euros. 